\title{
Evaluation of a low salinity water flooding with polymer gel treatment in Trinidad and Tobago
}

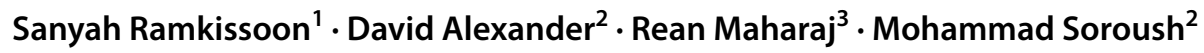

Received: 2 June 2020 / Accepted: 24 August 2020 / Published online: 6 September 2020

(c) The Author(s) 2020

\begin{abstract}
Trinidad and Tobago (TT) has a rich history of crude oil production and is still one of the largest oil- and gas-producing countries in the Caribbean region. The energy sector contributes approximately $35 \%$ of GDP to its economy; however, economic headwinds due to steadily decreasing oil production, low commodity prices and increased competition worldwide have highlighted the need for more economical methods of enhanced oil recovery (EOR) techniques. Although the use of low salinity polymer flooding for EOR has had success in other countries, critical information relating associated flooding system parameters such as soil type, additive type, adsorption characteristics, rheological (flow) characteristics, $\mathrm{pH}$ and salinity is not available and is critical if this type of EOR is to be implemented in TT. The nature and inter-relationship of these parameters are unique to a particular reservoir, and studies in this regard will provide key input data for simulations to produce near realistic projections of this EOR strategy. These projections can be used to evaluate the usefulness of a low salinity polymer flooding in TT and guide for the proper implementation of the strategy. The EOR 33 wells located in the lower Forest sands in Southern Trinidad was selected for study as they satisfied the screening criteria. Laboratory studies of the adsorption of xanthan gum concentrations of 0 to $4000 \mathrm{ppm}$ in combination with $\mathrm{NaCl}$ solutions $(0-40,000 \mathrm{ppm})$ onto gravel packed sand found that the mixture of $1000 \mathrm{ppm}$ polymer containing $1000 \mathrm{ppm} \mathrm{NaCl}$ exhibited the lowest adsorption capacity. The Langmuir coefficients were derived for each salinity, and together with results from the viscosity studies were inputted within the simulation models. Simulations of a sector of the EOR 33 projected that the highest oil recovery occurred using $\mathrm{NaCl}<2000 \mathrm{ppm}$ was $11 \%$ greater than water flood. A combination of brine $(\mathrm{NaCl}<2000 \mathrm{ppm})$ with gel technology (1000 ppm polymer) produced the highest oil recovery factor (54\%), almost twice that of water flooding, the highest average reservoir pressure and lowest water cut value. The improved performance characteristics observed using low salinity water flood with xanthan gum gel for injection can be associated with improved displacement efficiency and improved the sweep efficiency suggesting the strategy to be a technically feasible option for the EOR well in Trinidad.
\end{abstract}

Keywords Low salinity polymer flood $\cdot$ Xanthan gum $\cdot$ EOR $\cdot$ Water flood

\section{Introduction}

Hydrocarbons have been the primary driver of Trinidad and Tobago's (TT) economy for a very long time. From a historical perspective, the first successful oil well was drilled by

Rean Maharaj

rean.maharaj@utt.edu.tt

1 University of Trinidad and Tobago, Point Lisas, Trinidad and Tobago

2 Energy Systems Engineering Unit, University of Trinidad and Tobago, Point Lisas, Trinidad and Tobago

3 Process Engineering Unit, University of Trinidad and Tobago, Point Lisas, Trinidad and Tobago
Walter Darwent as early as 1866 and commercial oil production began near the famous Pitch Lake in La Brea in 1908. Although today TT is still one of the largest oil- and gas-producing countries in the Caribbean region contributing approximately $35 \%$ to GDP, in recent years, the oil sector has faced economic headwinds in the form of steadily decreasing oil production, falling international prices and increased competition worldwide. Crude oil production in Fig. 1 shows that TT averaged 107.19 MBBL/D from 1994 until 2019, reaching an all-time high of $156 \mathrm{MBBL} / \mathrm{D}$ in March of 2005 and a record low of 51MBBL/D in March of 2019 (https://tradingeconomics.com/trinidad-and-tobag o/crude-oil-production). 
Fig. 1 Crude oil production data from Trinidad and Tobago by year from 1994 to 2019 (https ://tradingeconomics.com/trini dad-and-tobago/crude-oil-produ ction)

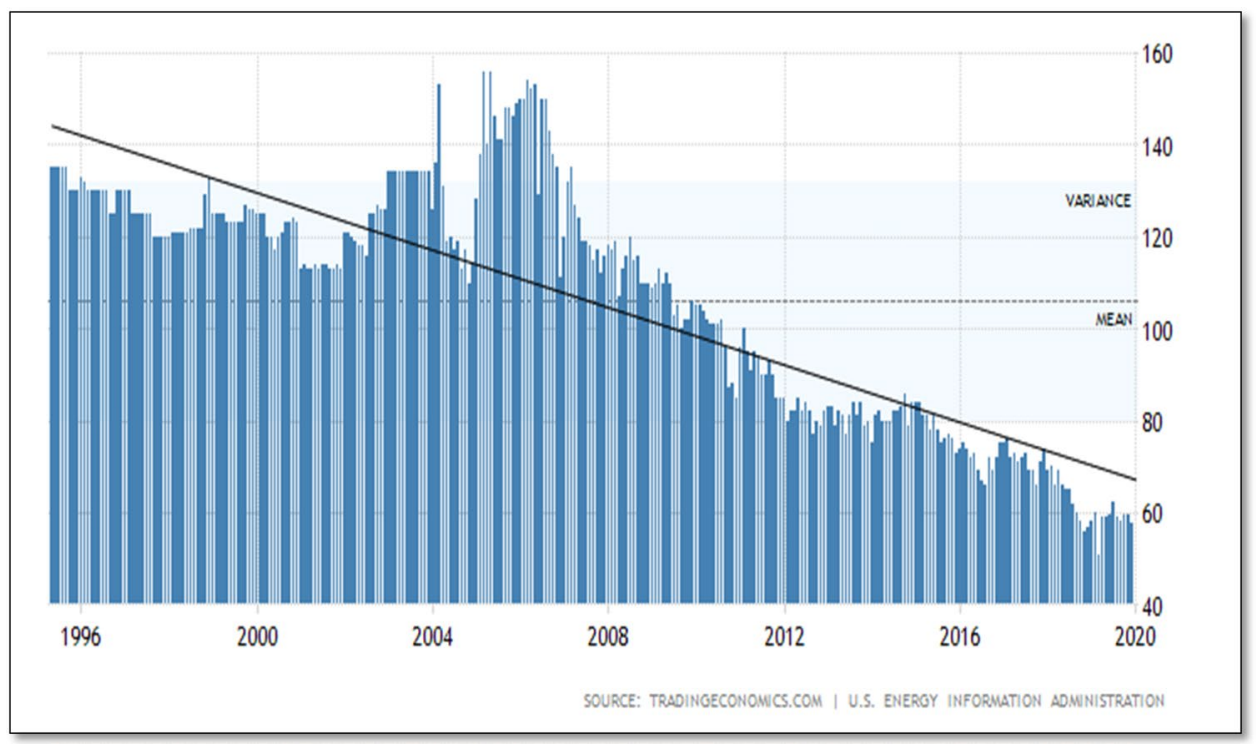

Although there has been some investment in deep water exploration which has led to new hydrocarbons discoveries being made, the issue of infrastructure presents a challenge for monetization. The decrease in the number of new discoveries of oil and gas reserves has prompted a need for enhancing recovery to meet the current and future energy demands. Trinidad and Tobago has produced over 320 MMbbls of oil via conventional secondary and EOR processes as shown in Fig. 2. The techniques used currently are WASP, steam flood and water flood with fourteen (14) operational projects as of 2017 (Ministry of Energy and Energy Industries 2019).

Of the techniques outlined in Fig. 2, water flood is one of the most common improved oil recovery (IOR) methods aimed at increasing depleted reservoir pressure and improving displacement efficiency. Water is readily available in the form of seawater, produced water and fresh water with the main difference between these sources being salinity. In TT, water flood has accounted for approximately $125 \mathrm{MMbbls}$ of oil since its introduction in 1953. (Ministry of Energy

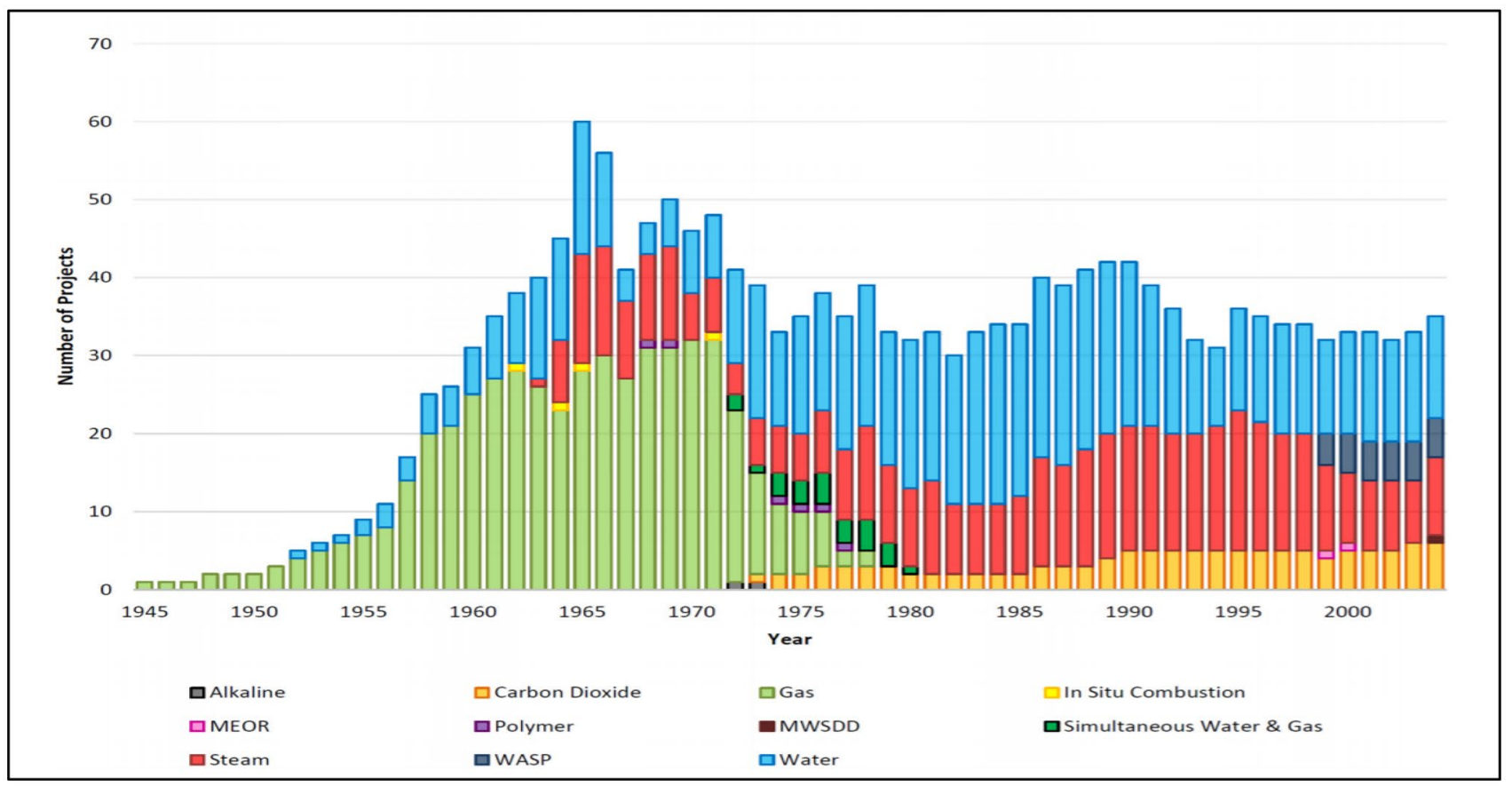

Fig. 2 Summary of IOR projects in Trinidad and Tobago (Source Sinanan et al. 2016) 
and Energy Industries 2019). There was a reduction in the number of projects in the 1980s mainly due to uneconomically high water cuts, inadequate water supply for injection as well as mechanical and operational problems (Sinanan et al. 2016). The low salinity water flood (LSWF) method is regarded as an emerging enhanced oil recovery (EOR) technique and hinges on the observation that an increase in oil recovery occurs with a decrease in salinity. Even though it may be a promising method, like water flood, it is still affected by viscous fingering (Tang and Morrow 1999).

Polymer flooding and polymer injection have become the most important chemical EOR methods used in sandstone reservoirs and have been receiving the attention of researchers. Utilization in the field has shown that polymer flooding can result in an increase in oil recovery by 5-30\% of OOIP (Abidin et al. 2012). Abidin A study by Leonhardt et al. (2014) utilizing the Schizophyllan synthetic polymer found that it was viscosity efficient and was resistant to tough reservoir conditions such as high temperature and salinity. Researchers Fondevila Sancet et al. (2018) studied the combination of xanthan gum and polyacrylamide and found the system exhibited desirable properties of mobility control. Despite improving the sweep efficiency and enhancing the oil recovery, polymer injection is negatively affected by adsorption on rock surfaces which reduces its sweep efficiency as well as the associated high permeability channels or thief zones, which allow fluid flow to bypass portions of the reservoir. To mitigate this occurrence, two types of polymer gel treatments are used today: in situ crosslinking gels and preformed particle gels (Coste et al. 2000, Van der Hoek et al. 2001). In situ crosslinking gels are placed in the near wellbore before crosslinking occurs where preformed particle gels are formed on the surface. After the injection of the polymer system in the matrix of a target zone, the components react and form a three dimensional polymer. The swollen pre-gelled particles do not dissolve in water and can move inside porous media reducing or fully blocking water flow through the pores. Specific attention is being paid to gel technology for profile modification treatments of heterogeneous reservoirs.

In TT, a recent investigation conducted by Coolman et al. (2020) to investigate the issue of the adsorption of polymer additives on material surfaces studied the adsorption and viscosity characteristics of the polymer flooding additives xanthan gum and aquagel on different soil types. Although the study offered critical information relating flooding system characteristics such as soil type, additive type, basic adsorption characteristics, and rheological (flow) characteristics, the influence of salinity on the performance of the polymer flooding agents was not investigated. This information is pertinent as many reservoirs in TT that are suitable for chemical EOR have high salinities such as onshore sandstone formations which have salinities in the range of 15,000-35,000 ppm. The addition of salts significantly reduces viscosity of the polymer solution consequentially affecting the required polymer dosage in field applications (Khamees and Flori 2018). Simulation studies conducted by Aluhwal (2008) on a Malaysian oil field demonstrated a clear inter-relationship between the concentrations of the polymer used (HPAM), adsorption characteristics, rheological behaviour and salinity suggesting a greater efficiency of the use of low salinity polymer flooding. The addition of salts was found to shift the position of the critical shear rate (where the onset of shear-thinning occurs) to a higher value, also reducing the slope of shear thinning region (Tam and Tiu 1990) as well as increasing the adsorption of the polymer (Ali and Mahmud 2015).

This study seeks to investigate the effects of a low salinity polymer flooding treatment using xanthan gum on the oil recovery factor of a non-sealing faulted reservoir in TT. Adsorption and viscosity experiments have been conducted using a range of polymer concentrations for $\mathrm{NaCl}$ solutions from low salinity to high salinity to obtain relevant adsorption data and the Langmuir isotherm parameters. The effect of salinity and polymer concentrations on the rheological (flow) properties has been studied. The laboratory and field data were embedded within models of a sector of the EOR 33 using CMG software to evaluate the performance of the strategy in the selected well in TT.

\section{Methodology}

\section{Laboratory study}

\section{Raw materials}

Gravel packed sand used in this study was ground and sieved, and a grain size between 20-40 mesh was collected. Refined xanthan gum polymer and laboratory grade sodium chloride $(\mathrm{NaCl})$ were used for the adsorption and viscosity studies.

\section{Adsorption studies}

The adsorption methodology followed the procedure outlined by Coolman et al. (2020). Working refined xanthan gum polymer solutions of concentrations of $(0,500,1000$, 2000,4000 and $8000 \mathrm{ppm}$ ) representing typical dosages used in industry were mixed in various sodium chloride (brine) concentrations at $0,1000,2000,10,000,20,000,35,000$ and 40000 ppm.

Measurements of absorbance readings were obtained using a HACH DR 5000 UV-VIS spectrophotometer machine at the $\lambda_{\max }$ wavelength value of $280 \mathrm{~nm}$ for xanthan gum. Absorbance values at different polymer concentrations

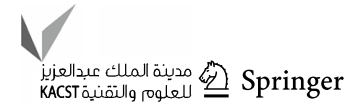


were recorded, and the data were used to generate calibration graphs for the quantitation of the adsorbed polymer on the gravel packed sand in subsequent experiments.

Samples (1 g) were mixed with solutions polymer at the various concentration and salinity values for $20 \mathrm{~min}$. These solutions were then allowed to sit and equilibrate for $10 \mathrm{~min}$ at room temperature before spectrophotometric analysis. The concentrations of the unabsorbed polymer in the supernatant liquid were obtained utilizing the calibration curve previously generated.

The adsorption behaviour of the various polymers was modelled using the Langmuir isotherm as described by Khamees and Flori (2018). The governing equation:

$C_{p}^{\wedge}=\frac{a C_{p}^{\wedge}}{1+b C_{p}^{\wedge}}$

where $a=\left(a_{1}+a_{2} C_{\mathrm{SEP}}\right) \sqrt{\frac{k_{\mathrm{ref}}}{k}}, C_{p}^{\wedge}$ adsorbed polymer concentration, wt $\%, a_{1}$ polymer adsorption parameter, dimensionless, $a_{2}$ polymer adsorption parameter, $\mathrm{ml} / \mathrm{meq}, b$ polymer adsorption parameter, $\frac{\text { volume of water }}{\mathrm{wt} \% \text { of polymer }}, C_{\mathrm{SEP}}$ effective salinity, $\mathrm{meq} / \mathrm{ml}$, $k$ permeability, md.

From the polymer adsorption results, Eq. 2 (a derivation of Eq. 1) was used to obtain the values of ' $a$ ', ' $b$ ' and 'b/a' for use in fine-tuning the simulator.

$\frac{1}{C_{p}^{\wedge}}=\frac{1}{a} \times \frac{1}{C_{p}}+\frac{b}{a}$

where $a=\left(a_{1}+a_{2} C_{\mathrm{SEP}}\right) \sqrt{\frac{k_{\mathrm{ref}}}{k}}, b$ polymer adsorption parameter, $\frac{\text { volume of water }}{\text { wt } \% \text { of polymer }}, C_{p}$ polymer concentration in water phase, wt $\%, C_{p}^{\wedge}$ adsorption value, $C_{\mathrm{SEP}} \mathrm{effective}$ salinity, $k$ permeability.

' $a$ ' is the first parameter in the Langmuir expression for the adsorption isotherm and is positive. ' $b$ ' is the second parameter for the adsorption isotherm associated with salt effects and must be non-negative. ' $b / a$ ' is the third parameter and must be no less than 1e-15.

\section{Viscosity studies}

The procedure employed for the viscosity studies was outlined by Coolman et al. (2020), and the study was conducted using an OFITE Testing Equipment Incorporated 8-speed Rotational viscometer. A fixed volume $(200 \mathrm{ml})$ of the samples (various polymer concentrations at different salinities) was stirred for $10 \mathrm{~s}$ after which viscosity readings for each sample was taken at speeds of 600,300, 200, 100, 60, 30, 6 and 3 RPM. This procedure was done at temperatures $60^{\circ} \mathrm{F}$, $100^{\circ} \mathrm{F}$ and $120^{\circ} \mathrm{F}$ all at atmospheric pressure. From the viscosity measurement, the following parameters were calculated for use in the simulator. viscosity, $\eta=\mathrm{KF} \frac{\theta}{\mathrm{RPM}}$

where $K$ machine constant for the bob and rotor $=300, F$ spring factor $=1.0, \theta$ viscometer deflection body

viscosity, $\eta=\frac{\text { shear stress, } \tau}{\text { shear rate, } \gamma}$

where shear stress $=1.067 \times \theta$, shear rate $=\mathrm{RPM} \times 1.7023$

Apparent viscosity, $\mathrm{AV}=\frac{600 \mathrm{RPM} \text { reading }}{2}$

\section{Results}

\section{Laboratory adsorption studies}

Working polymer solutions of the various concentrations of refined xanthan gum $(0,500,1000,2000,4000$ and $8000 \mathrm{ppm}$ of polymer) were mixed in sodium chloride (brine) solutions of concentrations $0,1000,2000,10,000$, 20,000, 35,000 and $40000 \mathrm{ppm}$. The corresponding absorbance readings were measured at the $\lambda_{\max }$ wavelength value of $280 \mathrm{~nm}$ and the data used to generate calibration graphs for subsequent quantitation of the quantity of adsorbed polymer on the gravel packed sand as outlined by Coolman et al. (2020). Figure 3 shows a typical calibration curve obtained for the xanthan gum at room temperatures at different salinities.

The results as depicted in Fig. 4 show the variation of the amount of xanthan gum adsorbed by $1 \mathrm{~g}$ of gravel packed sand at different salinity values.

The adsorption curves for refined xanthan gum clearly show a greater degree in adsorption occurred with an increase in the salinity of the flooding solution which is consistent with the findings of Ali and Mahmud (2015). Since the maximum polymer adsorption for the various salinities generally occurred at approximately $1000 \mathrm{ppm}$ polymer concentration and the xanthan gum adsorbed on the substrate in the polymer solutions containing $1000 \mathrm{ppm}$ salinity was shown to exhibit the lowest adsorption capacity for the sand, these data points were selected as inputs for the model simulation.

The procedure outlined by Khamees and Flori (2018) was used to obtain the Langmuir coefficients associated with the adsorption of the xanthan gum on the gravel packed sand which would be used as inputs in the subsequent simulation study. Figure 5 shows the typical plots of $1 /$ adsorption versus 1 /polymer concentration for the samples containing 35,000 ppm and $2000 \mathrm{ppm} \mathrm{NaCl}$ salinities, and Table 1 shows the coefficients obtained for each salinity as prescribed by the method outlined by Khamees 
Fig. 3 A typical polymer flooding calibration curve for the xanthan gum polymer
Fig. 4 Variation of the amount of xanthan gum adsorbed on $1 \mathrm{~g}$ of sand for different salinities
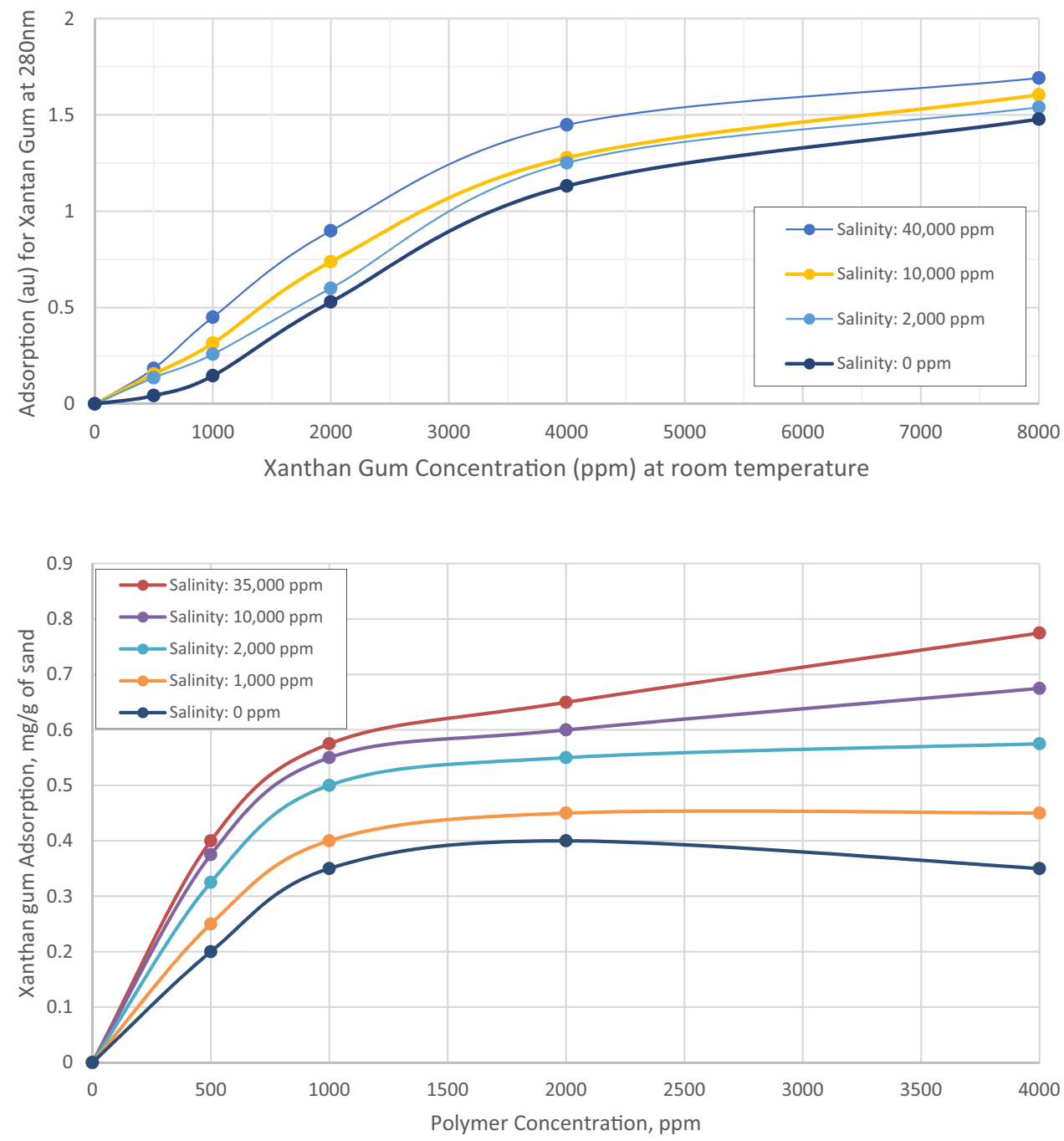

Fig. 5 Typical plots used to calculate the Langmuir isotherm model parameters for refined xanthan gum

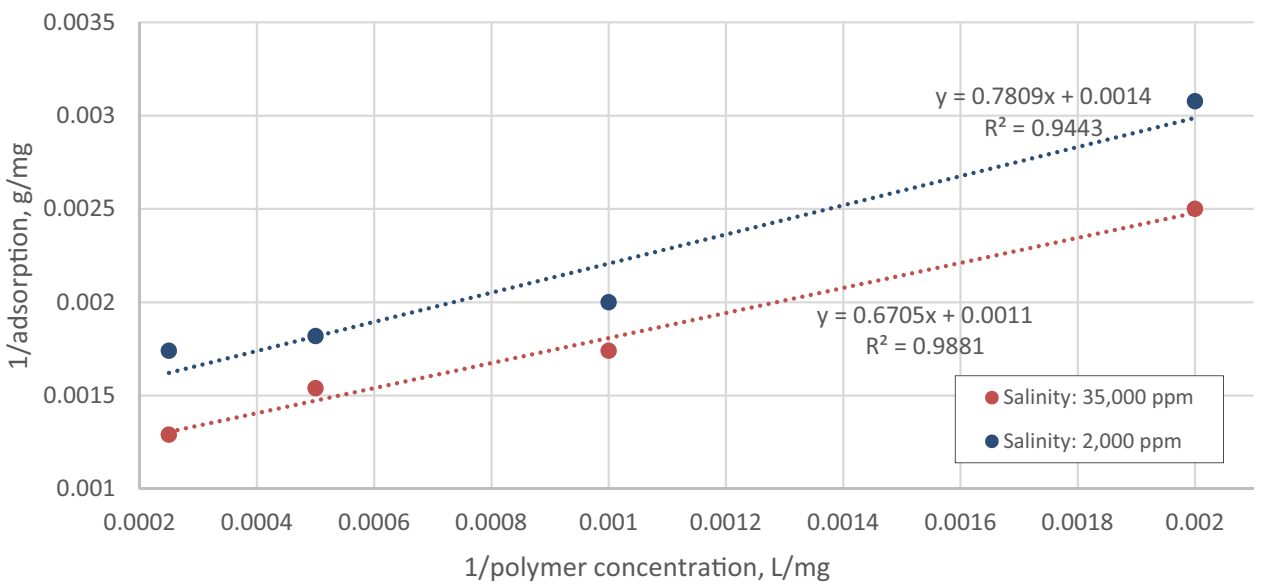

and Flori (2018). The results obtained for the $1000 \mathrm{ppm}$ xanthan gum sample containing $0 \mathrm{ppm} \mathrm{NaCl}$ were used in the fine-tuning the gel slug model, those for the $2000 \mathrm{ppm}$
$\mathrm{NaCl}$ were used for the combined low salinity water and gel model, and those for the $35,000 \mathrm{ppm} \mathrm{NaCl}$ were used for the combined high salinity and gel model. 


\section{Laboratory viscosity studies}

The acquisition of viscosity data is critical in the prediction of the suitability of the use of a polymer for EOR in a particular field. As described by Glatz (2013), the mobility ratio $(M)$ is calculated as the ratio of mobility $(\lambda)$ of the displacing fluid (water) to the mobility of the displaced fluid (oil), where the mobility of a particular fluid is its permeability $(\kappa)$ divided by its viscosity $(\mu)$. The mobility ratio $(M)$ is therefore dependent on the volumetric sweep efficiency of the system. If there is a large viscosity disparity between the displacing fluid and the displaced fluid (oil), $M$ will be $>1$, resulting in poor recovery. If $M$ is $<1$, as in the case when a viscous fluid (polymer) is used to increase the viscosity of displacing fluid, there is a greater chance of increasing the efficiency of oil recovery.

Figure 6 depicts the viscosity trends for the refined xanthan gum with increasing salinity and polymer concentration at $120^{\circ} \mathrm{F}$.

The expected trend of increasing apparent viscosity of the solutions as the polymer concentrations were increased was observed. A general trend of decreasing apparent viscosity as the salinity was increased was also recorded, and this increase became more pronounced as the polymer concentrations became higher. Figure 7 shows the variation of apparent viscosities of the refined xanthan gum mixtures containing $35,000 \mathrm{ppm}$ and $2000 \mathrm{ppm} \mathrm{NaCl}$ at varying temperatures. This plot re-emphasizes the earlier observation of
Table 1 Langmuir isotherm parameters for $1000 \mathrm{ppm}$ refined xanthan gum to be entered into the simulator
Fig. 6 Apparent viscosity plot for refined xanthan gum at $120^{\circ} \mathrm{F}$
Fig. 7 Apparent viscosity plot for refined xanthan gum with $35,000 \mathrm{ppm}$ and $2000 \mathrm{ppm}$ $\mathrm{NaCl}$ at varying temperatures

\begin{tabular}{lllllll}
\hline Salinity, ppm & $a, \mathrm{~g} / \mathrm{L}$ & $b, \mathrm{~g} / 0.001 \mathrm{~L}$ & $b / a$ & $a, \mathrm{lbmol} / \mathrm{ft} 3$ & $b, \mathrm{lbmol} / \mathrm{ft} 3$ & $(a / b)$ \\
\hline 0 & 0.739 & 0.001 & 0.002 & 0.046 & 0.092 & 0.500 \\
1000 & 0.943 & 0.002 & 0.002 & 0.059 & 0.100 & 0.588 \\
2000 & 1.281 & 0.002 & 0.001 & 0.080 & 0.112 & 0.714 \\
10,000 & 1.498 & 0.002 & 0.001 & 0.094 & 0.122 & 0.769 \\
20,000 & 2.408 & 0.004 & 0.002 & 0.150 & 0.241 & 0.625 \\
35,000 & 1.491 & 0.002 & 0.001 & 0.093 & 0.102 & 0.909 \\
40,000 & 1.127 & 0.001 & 0.001 & 0.070 & 0.063 & 1.111 \\
\hline
\end{tabular}
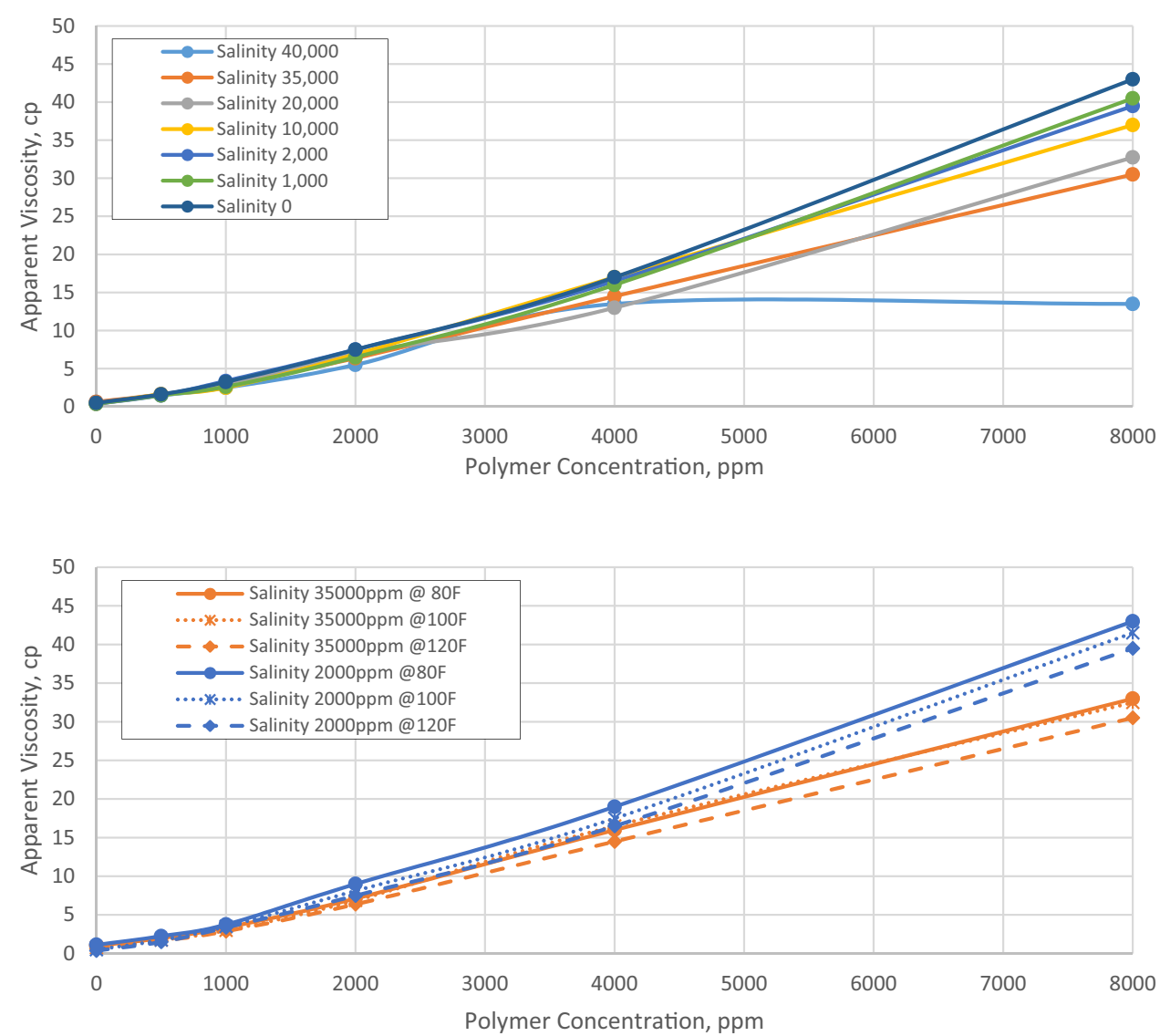
a well-defined trend of a decrease in apparent viscosity as salinity increases and also highlights the trend of a decrease in viscosity with increasing temperature.

\section{Screening criteria}

The selection of the reservoir for evaluation in this investigation was achieved by comparing the reservoir data of the candidate wells as documented by Mohammad-Singh and Singhal et al. (2004) with the general screening criteria requirements for EOR as stipulated by Taber et al. (1997) and Sheng (2015). The EOR 33 field project was selected for this study as the reservoir data met the general screening criteria requirements for low salinity polymer flooding EOR. The EOR 33 reservoir's data as presented by MohammedSingh and Singhal (2004) are shown in Table 2.

\section{Field description}

Geographically, Trinidad and Tobago lies at the mouth of the Orinoco River on the north-eastern continental shelf of South America. Figure 8 shows the location of EOR 33, the Lower Forest sands which will be investigated in this project. The Forest formation is located on the southern flank of the east-northeast trending the Fyzabad Anticline.

Table 2 Reservoir data EOR33 ( source Mohammed-Singh and Singhal 2004)

\begin{tabular}{ll}
\hline & EOR 33 \\
\hline Rock properties & \\
Area (acres) & 67 \\
Pay zone & L. Forest \\
Depth (ft) & 3000 \\
Thickness (ft) & 144 \\
Porosity (\%) & 32 \\
Permeability (md) & 125 \\
Oil saturation (\%) & 75 \\
Temperature $\left({ }^{\circ} \mathrm{F}\right)$ & 120 \\
Transmissibility (md-ft/cp) & 536 \\
Fluid properties & \\
Initial conditions & \\
Reservoir pressure (psi) & 1410 \\
Solution gas oil ratio (scf/bbl) & 193 \\
Oil formation volume factor (bbl/bbl) & 1.1 \\
Oil gravity ( ${ }^{\circ}$ API) & 19 \\
Oil viscosity (cp) & 16 \\
At CO ${ }_{2}$ flood start & \\
Reservoir pressure (psi) & 500 \\
Solution gas oil ratio (scf/bbl) & 50 \\
Oil formation volume factor $(\mathrm{bbl} / \mathrm{bbl})$ & 1.04 \\
Oil viscosity (cp) & 32 \\
\hline
\end{tabular}

The flank dips steeply, with an average dip of $30^{\circ}$ towards the south where bottom water exists in most pay intervals (Mohammed-Singh and Singhal 2004). The Forest formation lies below the Morne L'Enfer formation and unconformably overlies the Cruse Formation. It comprises a thick sequence of marine, shelfal to slope sandstones and claystones. The Lower Forest sands represent a flooding event overlying the Cruse Formation (Formations of Trinidad and Tobago 2019).

As shown in Fig. 9, the limits of individual oil accumulations are defined by shale-outs, faults and water-oil contacts. It is assumed that the faults are generally sealing; however, there are instances where flow across faults have been observed where porous pay on the two sides was adjacent (Mohammed-Singh and Singhal 2004).

The simulation model was built to understand the overall performance of reservoirs with similar characteristics to EOR 33. The model was a sector of the EOR 33 built to understand the full dynamics of the impact of the polymer in the presence of a fault and to understand the full field scale modelling of the polymer for EOR. The field data presented in Table 1 and the results of the adsorption and viscosity data from the laboratory studies were used to design the simulation models using the commercial software Computer Modelling Group Limited software (CMG-STARS).

\section{Simulation of a sector of the EOR 33}

A base block model was created with dimensions $820.1 \mathrm{ft}$, $410 \mathrm{ft}$ and $200 \mathrm{ft}$ in the $i, j$ and $k$ directions, respectively. A throw of 65 was used for the fault defined in grids $43 i$ to $83 i$ and $1 j$ to $41 j$. Figure 10 shows a $3 \mathrm{D}$ view of the synthetic model showing the fault and its throw.

The fault segment, $41 i, 1 j$ to $41 j$ and $1 k$ to $5 k$, was assigned a transmissibility of 0.5 . The model of the sector contained one injector well and one producer well. The injector well was controlled by surface water rate (STW) $1000 \mathrm{bbl} /$ day. The reservoir model properties were obtained from the Lower Forest Sand EOR33 as published in Lesson's From Trinidad's $\mathrm{CO}_{2}$ Immiscible Pilot Projects 1973-203 (Mohammed-Singh and Singhal 2004). The model of the sector was attributed a heterogeneous permeability with an average permeability of that of EOR33.

The model with heterogeneous permeability was created and simulated using CMG STARS using the Lower Forest Sand reservoir properties shown in Table 2. EOR simulations were run for 20 years after the end of the period of the injection and production history data. Each injection well had the constraints of $\max 3000 \mathrm{bbl} /$ day surface water rate or a $1,000,000 \mathrm{ft}^{3} /$ day surface gas rate. In the modelling of the sector of EOR 33, flooding using salinities of 0 , 100, 200, 500, 1000, 2000, 5000, 10,000, 20,000, 30,000

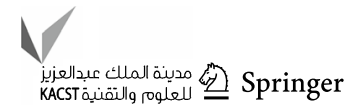


Fig. 8 Location of selected lower forest field EOR33 ( Source Mohammed-Singh and Singhal 2004)

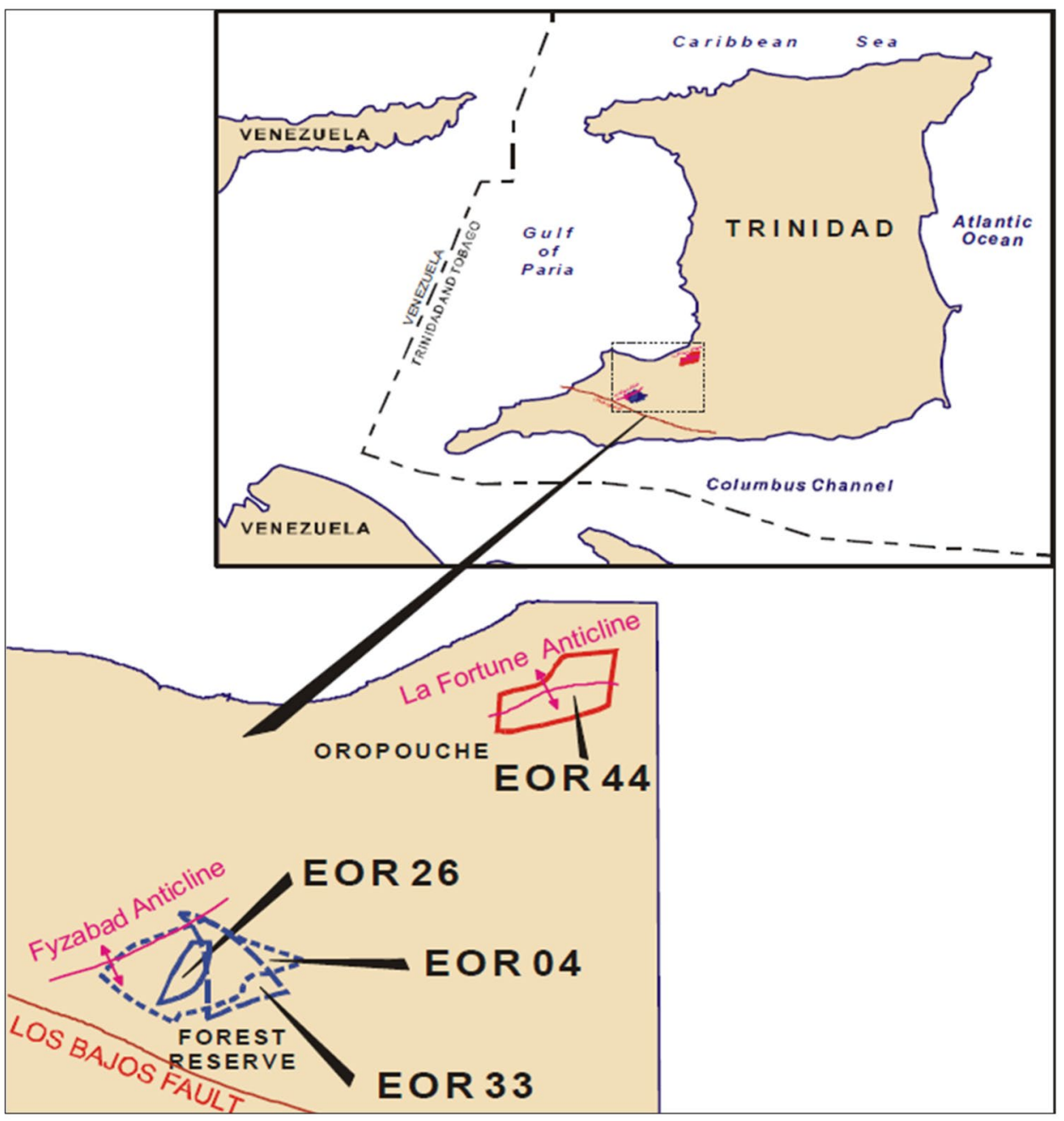

and $35,000 \mathrm{ppm} \mathrm{NaCl}$ alone as well as in conjunction with 1000 ppm cross-linked polymer gel was studied. For each salinity model, the simulated gel slug lasted a period of 150 days followed by LSWF at the respective salinities. The simulated gel slug was injected after $0.2 \mathrm{PV}$ pre-water injection and lasted for a period of 1276 days followed by the saline water flood for the respective salinities.

\section{Model simulation of EOR 33 sector}

The simulation results for all the EOR 33 sector models analysed are graphically shown in Fig. 11. Selected data for values of the oil recovery factors, average reservoir pressure and water cut percentage for the various models are shown in Table 3.

Compared to water flood, the introduction of brine into the water flood resulted in higher average pressures. This increase in pressure is due to an increase in fines migration associated with a decrease in salinity. The entrapment of fines in thin pore spaces causes a greater sweep into the reservoir and a decrease in water cut as observed. The entrapped fines also cause an increase in the average reservoir pressure which is usually associated with an increase in the oil recovery factor. This relationship is verified as the results show that the oil recovery factors increase with decreasing salinity and all the saline water flooding models have higher oil recovery factors compared to the water flood. The ion exchange between the introduced ' $\mathrm{Na}$ ' and the ' $\mathrm{Ca}$ ', as defined in the input reactions, causes the weakening of the bonds between the rock surface and the oil particles thereby freeing oil for production by promoting the desorption of the oil from the rock surface.

The highest oil recoveries occurred using low salinity models $(\mathrm{NaCl}<2000 \mathrm{ppm})$, and this was approximately $11 \%$ more than the recovery of the water flood. Water flooding mixtures with salinity values of 500, 1000 and $2000 \mathrm{ppm} \mathrm{NaCl}$ had very similar oil recoveries as did the mixtures with salinities of 10,000, 20,000 and 35,000 ppm $\mathrm{NaCl}$. One of the reasons for the higher oil recovery when low salinity water is injected instead of high salinity water is utilized can be attributed to the inherently lower water cuts of the low salinity water floods. 
Fig. 9 Structure contour map of lower forest sands ( Source Mohammed-Singh and Singhal, 2004)

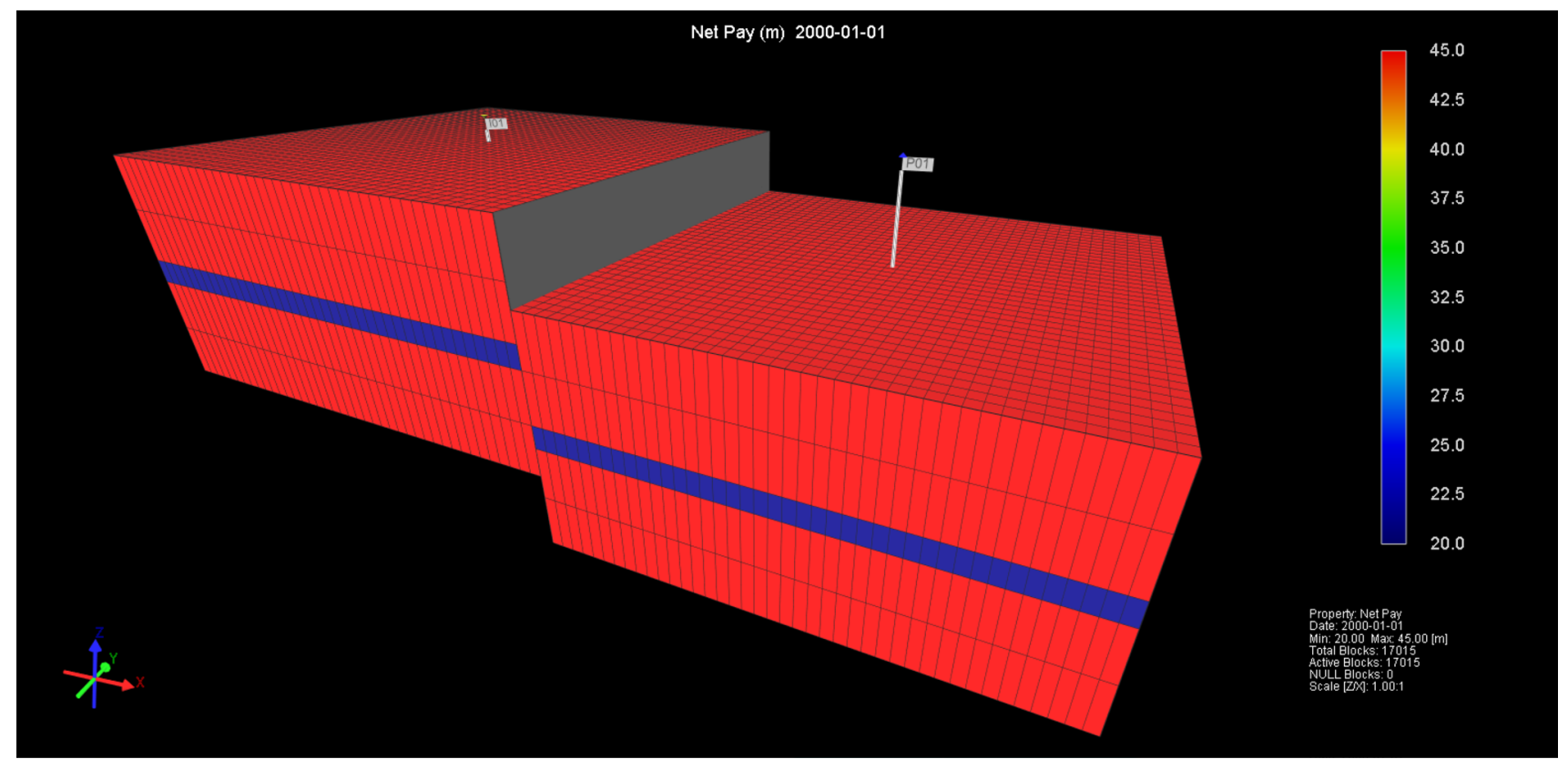

Fig. $103 \mathrm{D}$ view of the model of the sector of EOR 33 showing the fault and its throw

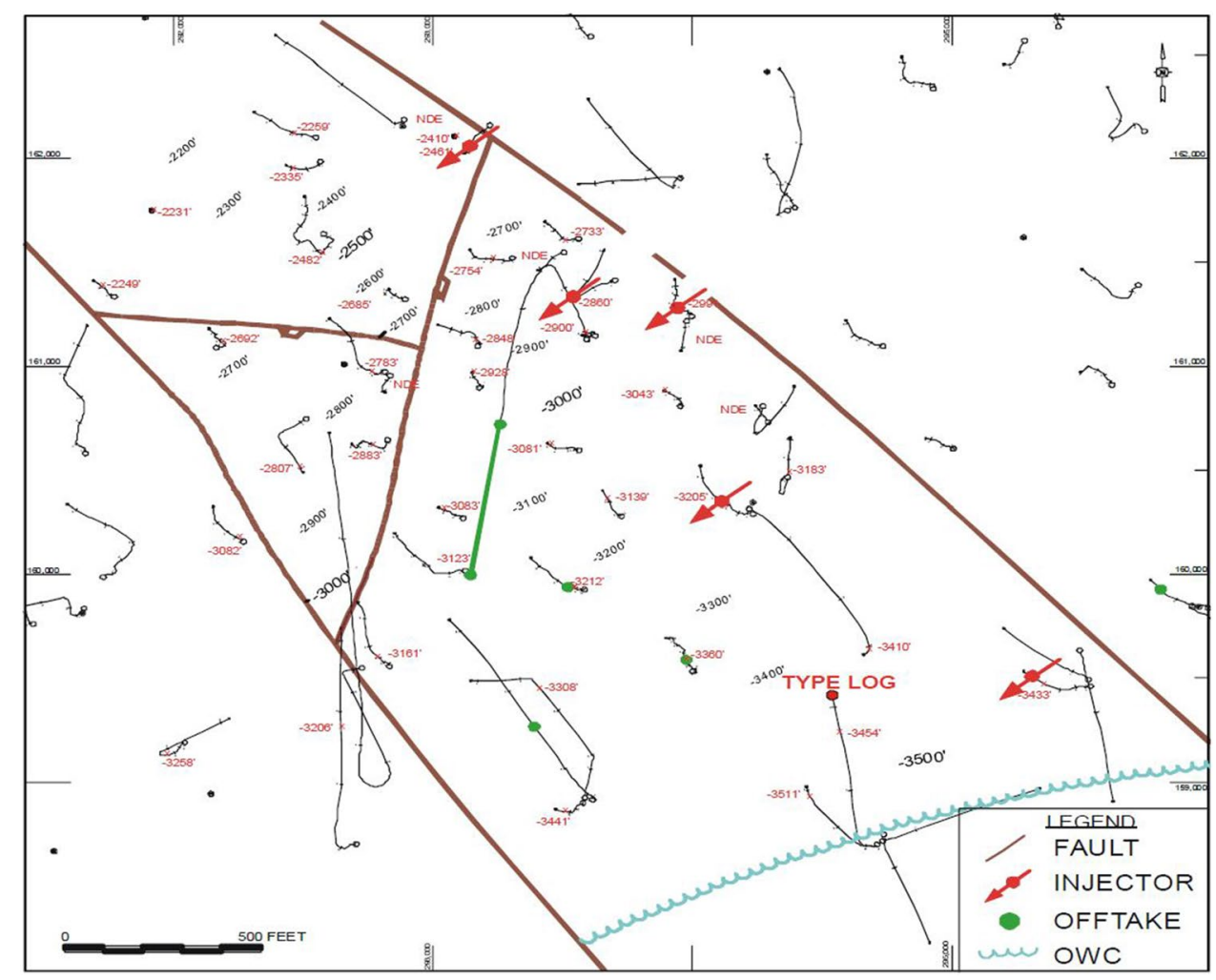

Net Pay $(m)$ 2000-01-01 
Fig. 11 Oil retention factors for all the models run for the sector of EOR 33
Synthetic Model Oil Recovery Factor

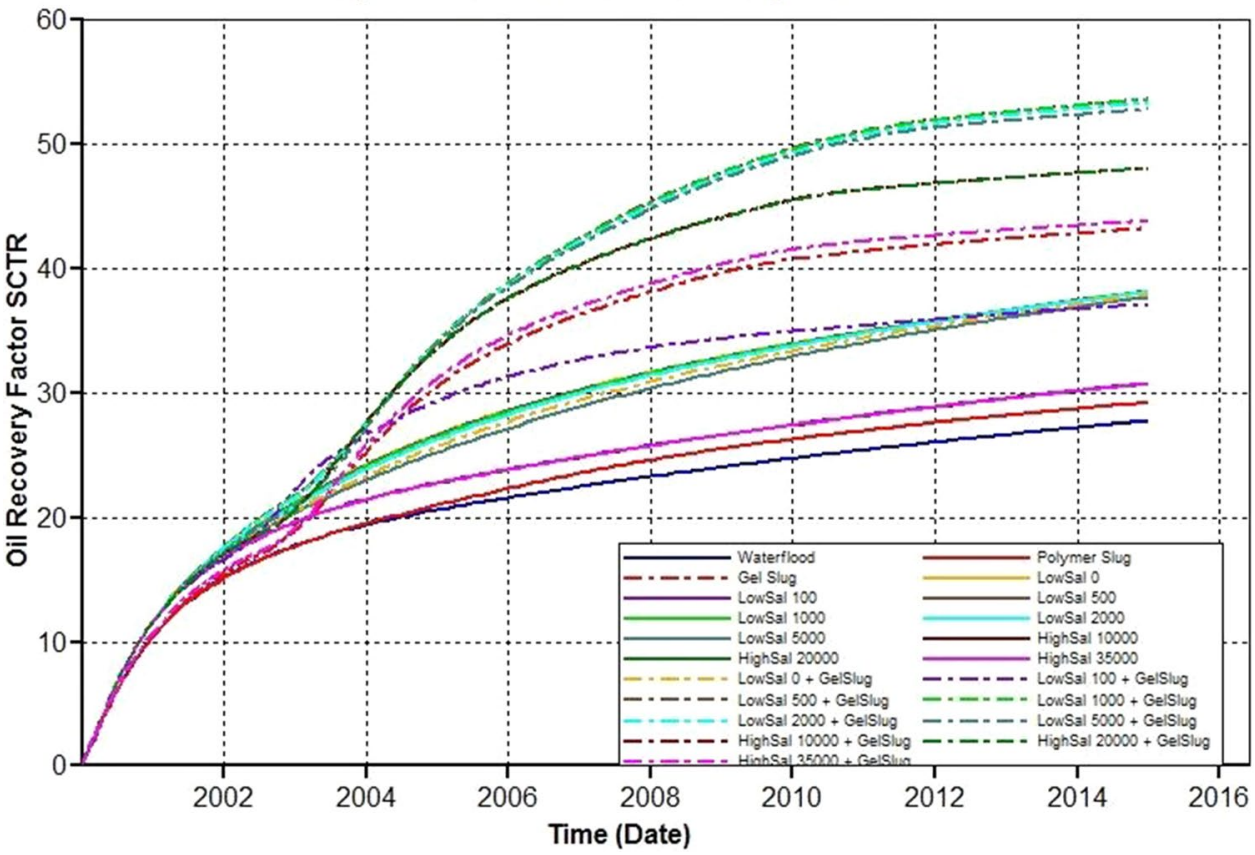

Table 3 Oil retention factors, average reservoir pressure and water cut percentage for the saline models

\begin{tabular}{llll}
\hline Model & $\begin{array}{l}\text { Ave pres } \\
\text { POVO SCTR } \\
(\mathrm{psi})\end{array}$ & $\begin{array}{l}\text { Oil recovery } \\
\text { factor SCTR }\end{array}$ & $\begin{array}{l}\text { Water cut } \\
\text { SCTR-\% }\end{array}$ \\
\hline Low salinity 500 ppm & 562.86 & 38.18 & 95.09 \\
Low salinity 1000 ppm & 563.03 & 38.16 & 95.07 \\
Low salinity 2000 ppm & 563.52 & 38.12 & 95.02 \\
Low salinity 5000 ppm & 566.13 & 37.71 & 94.63 \\
High salinity 10,000 ppm & 421.14 & 30.73 & 96.05 \\
High salinity 35,000 ppm & 421.14 & 30.75 & 96.05 \\
High salinity 20,000 ppm & 421.15 & 30.74 & 96.05 \\
Water flood & 423.15 & 27.76 & 96.44 \\
\hline
\end{tabular}

\section{Effect of combining LSWF and gel treatment on oil recovery}

Table 4 shows the results of the simulation exercises conducted on the various flooding mixtures and lists the oil recovery factors, average reservoir pressures and water cut percentages for the each model. The models of EOR33 were created at the various salinities and were simulated with $1000 \mathrm{ppm}$ polymer and $200 \mathrm{ppm}$ cross-linker (Gel).

The results show that the highest oil recovery factors (53-54\%) were observed for salinity $<2000 \mathrm{ppm} \mathrm{NaCl}$ and gel model. In fact, in these scenarios, the oil recovery factors were almost twice the value for the water flooding strategy (28\%). These models also recorded the highest average reservoir pressures and the lowest water cut values of all the models analysed, characteristics which are
Table 4 Oil retention factors, average reservoir pressures and water cut percentages for the saline water flooding and gel models

\begin{tabular}{|c|c|c|c|}
\hline Model & $\begin{array}{l}\text { Ave pres } \\
\text { POVO SCTR } \\
\text { (psi) }\end{array}$ & $\begin{array}{l}\text { Oil recovery } \\
\text { factor SCTR }\end{array}$ & $\begin{array}{l}\text { Water cut } \\
\text { SCTR-\% }\end{array}$ \\
\hline $\begin{array}{l}\text { Low salinity } \\
500 \text { ppm + Gel }\end{array}$ & 621.23 & 53.66 & 96.5 \\
\hline $\begin{array}{l}\text { Low salinity } \\
1000 \mathrm{ppm}+\mathrm{Gel}\end{array}$ & 617.24 & 53.62 & 96.6 \\
\hline $\begin{array}{l}\text { Low salinity } \\
2000 \mathrm{ppm}+\text { Gel }\end{array}$ & 611.46 & 53.34 & 96.76 \\
\hline $\begin{array}{l}\text { Low salinity } \\
5000 \mathrm{ppm}+\mathrm{Gel}\end{array}$ & 615.29 & 52.87 & 96.74 \\
\hline $\begin{array}{l}\text { High salinity } \\
10,000 \mathrm{ppm}+\text { Gel }\end{array}$ & 481.54 & 48.07 & 97.51 \\
\hline $\begin{array}{l}\text { High salinity } \\
20,000 \mathrm{ppm}+\mathrm{Gel}\end{array}$ & 478.54 & 48.06 & 97.53 \\
\hline $\begin{array}{l}\text { High salinity } \\
35,000 \mathrm{ppm}+\mathrm{Gel}\end{array}$ & 486.07 & 43.83 & 97.63 \\
\hline Gel slug & 500.47 & 43.24 & 97.35 \\
\hline Water flood & 423.15 & 27.76 & 96.44 \\
\hline
\end{tabular}

associated with greater sweep into the reservoir due to a combination of the blockage by fines migration, gel adsorption onto the rock surfaces and increases in water viscosity.

\section{Conclusion}

Laboratory adsorption studies found that the $1000 \mathrm{ppm}$ polymer concentration of xanthan gum containing $1000 \mathrm{ppm}$ salinity exhibited the lowest adsorption capacity for gravel 
packed sand. The Langmuir coefficients were derived for each salinity and along with results from the viscosity studies were used for the modelling simulations. The EOR 33 well located in the lower Forest sands on the southern flank of the east-northeast trending Fyzabad Anticline satisfied the selection criteria and was used for this study. Data obtained from simulation models for the sector of EOR 33 showed that compared to water flood, the introduction of brine resulted in higher average pressures, superior water cuts and oil recovery factor associated with improvements in displacement efficiency. The highest oil recoveries occurred using low salinity models $(\mathrm{NaCl}<2000 \mathrm{ppm})$ water flood which was approximately $11 \%$ more than the recovery of the water flood alone. Simulation models for the sector combining brine and gel technology show that the highest oil recovery factors $(53-54 \%)$ occurred for salinity $(<2000 \mathrm{ppm}$ $\mathrm{NaCl}$ ), twice the value for the water flooding strategy (28\%). These models also recorded the highest average reservoir pressures and the lowest water cut values. The low salinity water flood using xanthan gum polymer gel for injection proved to be a technically feasible strategy for the EOR well in Trinidad.

Open Access This article is licensed under a Creative Commons Attribution 4.0 International License, which permits use, sharing, adaptation, distribution and reproduction in any medium or format, as long as you give appropriate credit to the original author(s) and the source, provide a link to the Creative Commons licence, and indicate if changes were made. The images or other third party material in this article are included in the article's Creative Commons licence, unless indicated otherwise in a credit line to the material. If material is not included in the article's Creative Commons licence and your intended use is not permitted by statutory regulation or exceeds the permitted use, you will need to obtain permission directly from the copyright holder. To view a copy of this licence, visit http://creativecommons.org/licenses/by/4.0/.

\section{References}

Abidin AZ, Puspasari T, Nugroho WA (2012) Polymers for enhanced oil recovery technology. Procedia Chem 4:11-16

Ali M, Mahmud HB (2015) The effects of concentration and salinity on polymer adsorption isotherm at sandstone rock surface. IOP Conf Ser Mater Sci Eng 78(1):012038. https://doi.org/10.1088/1757899X/78/1/012038

Aluhwal O (2008) Simulation study of improving oil recovery by polymer flooding in a malaysian reservoir. University Teknologi Malaysia, Kualampur

Coolman T, Alexander D, Maharaj R et al (2020) An evaluation of the enhanced oil recovery potential of the xanthan gum and aquagel in a heavy oil reservoir in Trinidad. J Petrol Explor Prod Technol. https://doi.org/10.1007/s13202-020-00878-5
Coste J-P, Liu Y, Bai B, LI Y, Shen P, Wang Z, Zhu G (2000) Indepth fluid diversion by pre-gelled particles. Laboratory study and pilot testing. Society of Petroleum Engineers. https://doi. org/10.2118/59362-MS

Fondevila Sancet G, Goldman M, Buciak JM, Varela O, Fascio M, Manzano V, and Luong M (2018) SPE-190408-MS molecular structure characterization and interaction of a polymer blend of xanthan gum-polyacrylamide to improve mobility-control on a mature polymer flood. https://www-onepetro-org.research.libra ry.u.tt/download/conference-paper/SPE-190408-MS?id=confe rence-paper\%2FSPE-190408-MS

Formations of Trinidad and Tobago (2019) The geological society of trinidad and tobago. https://thegstt.org/geoattract/formations

Glatz G (2013) A primer on enhanced oil recovery. physics 240. Stanford University, Fall

Khamees TK, Flori RE (2018) Modeling the combined effects of water salinity and polymer rheology on the performance of polymer flooding and in-depth gel treatment. Society of Petroleum Engineers. https://doi.org/10.2118/190046-MS

Leonhardt B, Ernst B, Reimann S, Steigerwald A, Holding GmbH W (2014) SPE-169032-MS field testing the polysaccharide schizophyllan: results of the first year. https://www-onepetroorg.research.library.u.tt/download/conference-paper/SPE-16903 2-MS?id=conference-paper\%2FSPE-169032-MS

Ministry of Energy and Energy Industries (2019) Historical facts on the petroleum industry of Trinidad and Tobago. https://www.energ y.gov.tt/historical-facts-petroleum/

Mohammed-Singh LJ, and Singhal AK (2004) SPE 89364: lessons from Trinidad's $\mathrm{CO}_{2}$ immiscisble pilot projects 1973-2003. SPE J

Sheng JJ (2015). Status of polymer-flooding technology. https://wwwonepetro-org.research.library.u.tt/download/journal-paper/SPE174541-PA?id=journal-paper\%2FSPE-174541-PA

Sinanan B, Evans D, Budri M (2016) SPE 180853-MS: conceptualizing an improved oil recovery master plan for Trinidad and Tobago. SPE J. https://doi.org/10.2118/180853-MS

Taber JJ, Martin FD, Seright RS (1997) EOR screening criteria revisited part 1: introduction to screening criteria and enhanced recovery field projects. in spe reservoir engineering. https://www-onepe tro-org.research.library.u.tt/download/journal-paper/SPE-35385 -PA?id=journal-paper\%2FSPE-35385-PA

Tam KC, Tiu C (1990) Role of ionic species and valency on the steady shear behavior of partially hydrolyzed polyacrylamide solutions. Colloid Polym Sci 268:911-920

Tang G-Q, Morrow NR (1999) Influence of brine composition and fines migration on crude oil/brine/rock interaction and oil recovery. $\mathrm{J}$ Petrol Sci Eng 24:99-111

Trading Economics (2020) Trading economics 2020. https://tradingeco nomics.com/trinidad-and-tobago/crude-oil-production

Van der Hoek J, Botermans CW, Zitha PLJ (2001) Full blocking mechanism of polymer gels for water control. Society of Petroleum Engineers. https://doi.org/10.2118/68982-MS

Publisher's Note Springer Nature remains neutral with regard to jurisdictional claims in published maps and institutional affiliations. 